\title{
A população goianaense como guardiã do patrimônio cultural
}

Márcio Francisco de Carvalho ${ }^{1}$

\section{Resumo}

O presente texto tem como objetivo tratar o tema Educação Patrimonial a partir do trabalho da equipe participante do projeto "Educação Patrimonial do Campo: guardiões da paisagem e da cultura", realizado no município de Goianá, Minas Gerais. Apontando para a disparidade no acesso a este campo, por parte dos grupos sociais, o projeto tem como proposta ressaltar a importância da conscientização destes em se reconhecerem como sujeitos históricos comprometidos com a preservação patrimonial.

\section{Palavras-chave}

Educação Patrimonial. Guardiões do Patrimônio. Goianá-MG.

1. Graduado em História pela Universidade Federal de Viçosa, atua no campo de Educação Patrimonial, tendo realizado diversas oficinas e assessorias a professores das escolas públicas de Minas Gerais. E-mail: mar.carvalho@ yahoo.com.br. 


\title{
The goianaense population as a guardian of cultural heritage
}

Márcio Francisco de Carvalho*

\begin{abstract}
This article aims to address the issue from the Heritage Education team work of the project "Heritage Education Field: guardians of the landscape and culture" conducted at Goianá, Minas Gerais. Noting the disparity in access to this field by social groups, the project is proposed to emphasize the importance of awareness on these see themselves as historical subjects committed to preserving heritage.
\end{abstract}

\section{Keywords}

Heritage Education. Heritage Keepers. Goianá-MG.

* Graduated in History at the Federal University of Viçosa, which works with Heritage Education, realized a series of workshops and technical consultancy for teachers at the state schools of Minas Gerais. E-mail: mar.carvalho@ yahoo.com.br. 


\section{Introdução}

O trabalho com Educação Patrimonial tem por objetivo estimular a população a se tornar guardiã de seu próprio patrimônio. É neste sentido que o projeto "Educação Patrimonial do Campo: guardiões da paisagem e da cultura" busca, a partir dos princípios da Educação Popular, pautar sempre o diálogo e a conscientização dos envolvidos.

A equipe do projeto desenvolve atividades em Goianá, Coronel Pacheco, São João Nepomuceno e Rio Novo, municípios situados na Zona da Mata Mineira, na microrregião de Juiz de Fora. O trabalho realizado tem como público-alvo professores das escolas da rede pública, em especial as municipais, devido ao interesse da direção dessas escolas e a recepção encontrada nas Secretarias de Educação e Divisões de Educação e Cultura dos municípios.

Também é realizado um trabalho de Educação Patrimonial com moradores do Acampamento Denis Gonçalves do Movimento dos Trabalhadores Rurais Sem Terra (MST), localizado à margem da Rodovia MG-353, perímetro que liga o município de Cel. Pacheco a Goianá.

Parece ser consenso que a produção historiográfica recente tem dedicado amplos espaços e constituído inúmeras pesquisas no campo patrimonial, seja ele cultural, artístico, étnico etc. Esse movimento de abertura às novas perspectivas de pesquisa e atuação do profissional que queira trabalhar com o patrimônio tem sua gênese na esteira das críticas aos modelos sociológicos hegemônicos e normativos que perduraram durante o século XIX e tiveram enorme peso e influência nos trabalhos sobre patrimônio no século XX.

De acordo com o Art. 215 da Constituição Brasileira de 1988, patrimônio cultural seria a soma dos bens culturais de uma comunidade ou grupo (BRASIL, 1988). Contudo, o tema patrimônio já vem sendo discutido há bem mais tempo, como podemos observar no Decreto-Lei № 25, de 1937, que descreve:

Patrimônio cultural é o conjunto de bens móveis e imóveis existentes no país cuja conservação seja de interesse público, quer por sua vinculação a fatos memoráveis, quer por seu excepcional valor arqueológico ou etnográfico, bibliográfico ou artístico (BRASIL, 1937, não paginado).

Portanto, pode-se observar que o patrimônio cultural pertence à população e a ela se destina, juntamente com os órgãos públicos, o encargo da preservação.

Uma releitura do que deve ser compreendido enquanto patrimônio e de sua evolução, se observada pela ótica exposta por Haroldo L. Camargo (2005, p. 1), é a de que o patrimônio "não evolui para tornar-se cada vez mais refinado, mas transforma-se em razão das demandas sociais". Tal reflexão nos permite entender, portanto, que há uma contribuição do homem ou de um grupo sobre o que se pode entender como patrimônio ou no que se supõe ser uma representação geral do social neste monumento patrimonial.

Neste sentido, faz-se necessária a adoção de políticas patrimoniais pluralistas, capazes de valorizar a diversidade ambiental, as heterogeneidades culturais e as múltiplas identidades, de modo a promover a convivência harmoniosa entre o homem e o meio, garantindo a inclusão social dos cidadãos (PELEGRINI, 2006). Assim, cabe-nos delimitar uma diferenciação entre aqueles que têm acesso ou interferência sobre o patrimônio e aqueles que, à mercê de sua sorte, veem seus símbolos culturais se perderem no tempo. Acredito que certos grupos sociais, por falta de acesso a informações, acabam ficando 
à margem da interpretação no que se refere ao patrimônio, e outros, no caso a elite, por deter tais informações, impõe o que viria a ser uma referência de patrimônio. Não creio, no entanto, que as coisas aconteçam apenas por vontade de um grupo específico ou mesmo que as mudanças não se processem. O que chamo atenção é para a disparidade que há acerca da informação. Assim, o historiador D. Byrne (1991 apud FUNARI, 2001) afirma ser comum os grupos dominantes usarem seu poder para promover seu próprio patrimônio, minimizando, ou mesmo negando, a importância dos grupos subordinados ao forjar uma identidade nacional à sua própria imagem.

O campo da preservação da memória sempre foi, e continuará sendo, local de conflitos, nos quais vários grupos tentam impor a "sua memória" como relevante. Penso que, neste sentido, a informação torna-se fundamental, pois mais uma vez, neste palco de conflitos, a pouca orientação das camadas populares dificulta a guarda da memória popular. Sendo assim, a Educação Patrimonial constitui-se um instrumento fundamental para tornar o patrimônio mais democrático e inclusivo.

Portanto, no bojo da abertura histórica é que se presencia, no termo patrimônio, conflitos não só econômicos, como também outros: culturais, sociais, políticos, de gênero, de idade (FUNARI; CARVALHO, 2005). Parece-me correto questionar: quais as reais condições de se buscar a valorização da diversidade e permitir os impulsos dos diversos atores sociais no resgate e na guarda de seus monumentos patrimoniais?

Ainda de acordo com Funari e Carvalho (2005), a criação da UNESCO (Organização das Nações Unidas para a Educação, Ciência e Cultura) gerou uma sólida propagação da diversidade que envolve as comunidades, de maneira geral, na preservação e na gestão pública de seus bens culturais. No entanto, para além deste esforço, o que se presencia é uma uniformização cultural, principalmente se tomamos como base a expansão e a solidificação dos meios de comunicação em massa. Sendo assim, a comunicação e a informação acerca da diversidade cultural, talvez ainda não se prestem a maiores esclarecimentos sobre patrimônio cultural para a população.

\section{Educação patrimonial como instrumento de cidadania}

O caminho a percorrer para uma consciência da comunidade acerca de seus valores se constitui a partir do diálogo. Sendo assim, faz-se necessária a utilização de novas ferramentas e, neste sentido, a Educação Patrimonial constitui-se como um instrumento de "alfabetização cultural" que possibilita ao indivíduo fazer a leitura do mundo que o rodeia, levando-o à compreensão do universo sociocultural e da trajetória histórico-temporal em que está inserido. (HORTA; GRUNBERG; MONTEIRO, 1999).

Projetos de Educação Patrimonial têm sido alvos de políticas públicas por todo país. Em Minas Gerais, a Lei do ICMS Cultural (Lei no 12.040, de 28 de dezembro de 1995) vem incentivando os municípios mineiros a adotarem ações para proteção e preservação do patrimônio histórico, valorizando o trabalho das prefeituras municipais em relação à conservação de seus patrimônios.

A educação patrimonial, sendo um instrumento para a cidadania, deve tomar o cidadão como sujeito histórico, pois, por cidadania, devemos entender os direitos de todas as esferas da vida humana (ARENDT, 1987). Neste sentido, deve permitir à comunidade reapropriar-se de lugares, histórias, objetos, monumentos e tradições que foram ou são importantes do seu ponto de vista. Para que ocorra esta (re)apropriação, é necessário a promoção de propostas de aprendizagem que atraiam a atenção de 
pessoas de todas as idades, inclusive crianças e adolescentes, e que, de uma forma lúdica e prazerosa, possibilitem a aquisição e registro de novos conhecimentos. Por exemplo, as escolas que adotarem este tipo de metodologia conseguirão provocar, em seus estudantes, um interesse grande para o aprendizado.

$\mathrm{O}$ que se pretende com este texto é enfatizar que esse processo de ressignificação intensificou-se nos últimos anos, mas as raízes da uniformização são muito mais antigas e remontam ao domínio do capital pelo mundo (FUNARI, 2001).

Desta forma, para além do discurso comumente aceito da valorização e da luta pela preservação da diversidade cultural, social, natural e ambiental, quais os espaços possíveis para que cada grupo/ator social sintase respaldado pelos patrimônios culturais da sociedade? Quais as ferramentas possíveis desses atores para a luta por esses direitos?

No debate acerca do patrimônio, tornamse perceptíveis as divergências em torno da capacidade ou não de grupos que outrora tinham sido apartados de seus diretos à preservação e manutenção patrimonial, de gerir e impulsionar a riqueza monumental. De acordo com Funari (2001), no Brasil, o cuidado com o patrimônio sempre esteve a cargo da elite, cujas prioridades têm sido tanto míopes como ineficazes. Não defendo uma generalização acerca de tal compreensão, pois entendo que nem tudo feito pelas elites foi equivocado, assim como muito do que foi preservado do patrimônio no Brasil devese à ação desses grupos. Apesar da importância de tal preservação, o questionamento aqui apresentado tem relação com quem e para quem o patrimônio é representado. Sendo assim, creio na possibilidade da inserção de outros grupos na apropriação e na criação de outras formas de se preservar este patrimônio.

Não é novidade que o processo histórico de formação do Estado sempre teve como base o distanciamento, para não falar em abismo, entre as possibilidades culturais, econômicas, sociais, informativas, dentre outras, das classes que o compõem. O perfil antagônico entre esses setores marcou e marca ainda nossa sociedade. Portando, no caso do acesso ao patrimônio, não poderia ser diferente. A questão posta em discussão é: com profunda desigualdade, quais as bases materiais e culturais que outras classes (que não a elite) têm para fazer "frente" na apropriação dos monumentos patrimonias? Qual a capacidade informativa que as camadas populares têm para respaldar a gerência do patrimônio? Este ponto se caracteriza por certa dualidade nas compreensões de diversos autores, que variam desde um conservadorismo elitista até posicionamentos mais arrojados que incentivam a tomada cultural destes elementos pelo povo.

Um posicionamento emblemático a respeito desta questão é o do arquiteto Marco Aurélio N. F. de Queiroz (1984) ao advogar a respeito das limitações da população acerca da gerência patrimonial. De acordo com o autor, como uma população subempregada, subnutrida e pouco informada sobre o valor da sua própria cidade vai ter elementos ou interesse em discutir problemas de planejamento urbano e, sobretudo, de preservação de belos casarões coloniais? Queiroz crê ser bastante utópico pretender esse nível de participação da população da comunidade local na problemática da preservação. Apesar de reconhecer tais limitações expostas pelo autor, não poderia deixar de analisar criticamente tais premissas. Primeiro porque a problemática existe devido à falta de informação a todos os grupos, caracterísitica de uma sociedade com possibilidades restritas a um pequeno setor. Segundo, pelo fato de que, por falta deste conhecimento, não se possa haver a apropriação de outros grupos em relação à questão patrimonial. Seria fácil concordar com a ideia de que as classes populares não têm interesse em preservar casarões ou outros edifícios que, teoricamente, não se associam à sua história. Entretanto, 
se pensamos que a história imbricada nestes conjuntos arquitetônicos condiz com a história de vida da população, temos claro o papel dela na preservação, uma vez que adentra neste ponto o fator político existente no discurso historicizado daquele ambiente.

Não se trata, neste embate teórico, de referendar ou não o que deva ser tomado como patrimônio, pois devemos nos pautar pela preservação tanto do patrimônio erudito, como do popular, a fim de democratizar a informação e a educação em geral. Acima de tudo, devemos lutar para que o povo assuma seu destino, oferecendo acesso ao conhecimento, para que possamos trabalhar, como acadêmicos e como cidadãos, com o povo e em seu interesse (FUNARI, 2001).

\section{Guardiões do patrimônio goianaense}

Nesta perspectiva de apropriação do povo como guardião do patrimônio, é que surge a proposta de trabalho realizada pela equipe do projeto "Educação Patrimonial: Guardiões da Paisagem e da Cultura", tendo como públicoalvo os municípios mineiro de São João Nepomuceno, Rio Novo, Cel. Pacheco e Goianá.

Neste texto, nos deteremos em descrever os objetivos, desenvolvimentos e resultados alcançados nas oficinas realizadas, no ano de 2011, em Goianá. A proposta do trabalho no município esteve pautada na utilização da Educação Patrimonial como instrumento para a cidadania e o reconhecimento da população enquanto guardiã do próprio patrimônio.

Goianá está localizado na Zona da Mata Mineira, na microrregião de Juiz de Fora. Com aproximadamente quatro mil habitantes, o município emancipou-se há menos de vinte anos, mas sua origem remonta à segunda metade do século XIX quando ainda era Povoado de Santo Antonio do Limoeiro.

$\mathrm{O}$ trabalho referente à Educação
Patrimonial vem sendo realizado em parceria com a Divisão de Educação do município. O projeto proposto pela equipe de estudantes e docentes da Universidade Federal de Viçosa está inserido em Goianá no programa de capacitação de professores da rede municipal e, portanto, são realizadas atividades com professores/as da Escola Municipal Prefeito José Loures Ciconeli.

O município, diferente de muitas outras localidades que deixam os bens patrimoniais à mercê do tempo, vem implantando um programa de preservação patrimonial importante para sua história, tendo um Conselho Deliberativo constituído paritariamente por representantes do Poder Público e da Sociedade Civil Organizada, nomeado Conselho do Patrimônio Cultural (COMPAC). Portanto, o trabalho no município de Goianá com os/as professores/ as desenvolve-se no sentido de reforçar esta proteção, contemplando a questão de que não compete a preservação patrimonial somente aos órgãos públicos, mas também se faz necessário o apoio de sua população.

O trabalho com Educação Patrimonial nas escolas fortalece a relação das pessoas com suas heranças culturais, estabelecendo, assim, um melhor relacionamento com estes bens. Ao perceber-se como responsável pela valorização e preservação do patrimônio, a população se vê como guardiã de sua própria memória.

Neste sentido, as atividades em Goianá são realizadas a partir de oficinas nas quais há uma participação fundamental dos envolvidos, seja dos integrantes da equipe do projeto, seja dos/das professores/as da escola, uma vez que tanto um grupo quanto o outro se dedica aos trabalhos teórico e empírico, pesquisando a história do município.

\section{Educação Patrimonial: a construção das identidades}

A primeira oficina oferecida em Goianá recebeu o tema "Educação patrimonial: a 
construção das identidades" e buscou trazer ao público participante um entendimento acerca do processo da construção da identidade. Para tanto, foram utilizados a música "Upa, upa! (Meu trolinho)", de Ary Barroso, o vídeo "Identidade" 2 e o filme "Tapete Vermelho". Todo esse material serviu de instrumentos para nortear um debate no qual os participantes tiveram a oportunidade de contribuir para o desenvolvimento da oficina.

O tema desta oficina decorreu do entendimento de que, em um trabalho sobre a memória de um grupo, deve-se refletir sobre a "construção das identidades", compreendendo que qualquer identidade é construída e que cada tipo de processo de construção de identidade leva a um resultado distinto no que tange à constituição da sociedade (CASTELLS, 2000). Assim sendo, um dos objetivos desta primeira oficina foi o de compreender que o patrimônio cultural materializa-se, tornando visível o sentimento evocado pela cultura e pela memória, permitindo, assim, a construção das identidades coletivas, fortalecendo os elementos das origens comuns e constituindo o passo decisivo para a continuidade e sobrevivência de uma comunidade (IEPHA, 1996). No entanto, o entendimento da construção das identidades, não pode ser referenciado como um processo acabado. De acordo com Hall (1996), ao invés de tomar a identidade por um fato que, uma vez consumado, passa, em seguida, a ser representado pelas novas práticas culturais, deveríamos pensá-la, talvez, como uma "produção" que nunca se completa, que está sempre em processo e é sempre constituída interna e não externamente à representação.

Sendo tal oficina proponente deste debate, o objetivo proposto foi fundamental para a continuidade dos trabalhos, pois, nesta atividade, pode-se compreender que, para além desse aspecto da construção de identidade, a noção de patrimônio cultural diz respeito à herança coletiva que deve ser transmitida às futuras gerações, de forma a relacionar o passado e o presente, permitindo a visão do futuro, dentro do conceito de desenvolvimento sustentável (IEPHA, 1996). No que se refere diretamente aos patrimônios públicos, a educação patrimonial facilita o processo de conservação de lugares históricos, da natureza e da cultura. Portanto, compreendemos que, a partir de uma metodologia simples, é muito mais fácil que a comunidade se dê conta do quanto é essencial para sua existência preservar seu patrimônio.

Os resultados alcançados nesta oficina foram significativos e vistos como de curto prazo, quando tomamos as oficinas posteriores como referência. Conseguiu-se desenvolver nos educadores o conceito de identidade, partindo do individual para o coletivo, além de ter estimulado sua capacidade investigativa e criativa para a elaboração de materiais, contribuindo para uma busca da recuperação e da preservação do patrimônio material e imaterial goianaense.

\section{Conhecendo a cidade através do olhar cidadão}

A segunda oficina, denominada "Conhecendo a cidade através do olhar cidadão", constituiu-se de uma caminhada pedagógica de "reconhecimento" da cidade por seus próprios moradores, no caso, os/ as professores/as. O intuito deste trabalho de campo foi, a partir do olhar dos participantes, relatar o espaço presenciado, assim como a paisagem local sob uma perspectiva cidadã. Desta forma, acredita-se que:

2. O vídeo foi produzido em 2011 pela própria equipe do projeto a partir de fotos antigas de elementos referentes a patrimônio cultural e relatos acerca do patrimônio imaterial. 
humanos, mediante estruturas mentais correntes no universo sociocultural de cada época e de cada povo (MACIEL, 2009, p. 32).

Os/As professores/as e a equipe do projeto foram distribuídas em grupo e puderam fazer diversos percursos, mas sempre com a intenção de observarem a paisagem e as características históricas de sua cidade. No retorno à escola, foi realizada a segunda parte da oficina, a partir da qual se pôde observar que a caminhada possibilitou o enriquecimento do debate e fortaleceu o desenvolvimento do trabalho acerca da Educação Patrimonial. Neste debate, os participantes puderam construir suas perspectivas e observações de acordo com o percurso realizado pelas ruas e praças da cidade, por meio do qual aguçaram o olhar sobre a paisagem do município goianaense.

Sendo assim, alguns relatos dos envolvidos referiram-se ao fato de que já haviam feito o mesmo trajeto outrora, mas nunca com o olhar voltado para o patrimônio goianaense. Dessa forma, a paisagem cultural torna-se uma tribuna de onde os sujeitos falam de sua cosmovisão sob o prisma dos espaços conhecidos, tentando encontrar a especificidade do seu lugar de vida num quadro maior (MACIEL, 2009).

\section{Conhecendo a cidade através do olhar cidadão: sistematizando o patrimônio goianaense}

A terceira atividade "Conhecendo a cidade através do olhar cidadão: sistematizando o patrimônio goianaense" teve por objetivo a apresentação de um trabalho de campo realizado pelos/as professores/as durante o intervalo da segunda para a terceira oficina.

O trabalho de campo teve como demanda visitar os bairros da cidade, assim como as comunidades, povoados e fazendas da zona rural, e adquirir informações sobre esses lugares. Por meio destas atividades, os participantes transcreveram relatos orais dos moradores, levando em conta origem, cultura popular, lendas, atividades econômica e religiosa, entre outras questões. Uma das lendas foi relatada pelo Sr. Sebastião Paulino Ferreira ${ }^{3}$, de 86 anos, nascido na Fazenda Capoeirinha. Em seu relato, os moradores antigos afirmavam que ouviam, nas noites escuras, correntes arrastando no porão da fazenda, pois na época da escravidão era onde prendiam os escravos.

Outras lendas, assim como os mais diversos depoimentos coletados pelos/pelas professores/ as e pela equipe do projeto, deverão ser usados como material didático nas escolas. Portanto, o que se objetivou com esta atividade foi agrupar todo o material coletado para utilizá-lo, com os alunos da escola envolvida, efetivando-se, assim, o trabalho com a comunidade escolar, e como instrumento de familiarização da comunidade goianaense com sua história. Entendemos que a necessidade da Educação Patrimonial nos currículos e programas escolares dá-se pelo fato de que ainda há uma falta de esclarecimento popular sobre a importância da preservação de nosso Patrimônio, para não dizer uma deseducação coletiva (LEMOS, 1987).

Sendo a educação popular, como proposta por Paulo Freire (1987), a construção de um processo, é difícil pensar em resultados em tão pouco tempo. Porém, a perspectiva patrimonial dos envolvidos está se configurando e, para o futuro, as especificidades de cada comunidade, com modos diferentes de se relacionar ao saber acadêmico, revelará os impactos causados.

Portanto, espera-se no município de Goianá que professores e alunos das escolas possam aderir à temática educação patrimonial e, concomitante a este trabalho no ambiente escolar, a população goianaense possa se ver enquanto guardiã de seu patrimônio.

3. A transcrição deste relato assim como outros da Fazenda Capoeirinha foi realizada pelos/as professores/as da Escola Municipal de Goianá como parte das atividades propostas pelo projeto. 


\section{Considerações Finais}

Tendo como posicionamento o sujeito comoarticuladordo movimentoda história, capaz de mudá-la e recriá-la, o que proponho neste trabalho é, a partir de um relato de experiência, reforçar a ideia de inserção da população como protagonista no que se refere à apropriação do patrimônio cultural, pois, observado de uma perspectiva histórica, o povo sempre esteve à margem deste processo de preservação.

Portanto, não se parte apenas da simples delegação de funções a entidades autárquicas ou governamentais, pois o povo, enquanto agente e sujeito histórico, deve, apesar de uma série de impecilhos, tomar este espaço como seu, já que a ele se destina.

Conhecedores de que a cultura e a memória de um povo são os principais fatores de sua coesão e identidade e responsáveis pelos liames que unem as pessoas em torno de uma noção comum de compartilhamento e identidade, noção básica para o senso de cidadania (IEPHA, 1996), a população passa a se relacionar com o patrimônio de forma pessoal e a preservação torna-se um assunto muito sério para a comunidade. A discussão, gerada nos processos educativos, começa a fazer parte do cotidiano das pessoas, uma vez que elas se reconhecem e veem no patrimônio um pedaço de sua história e de seus descendentes.

Assim, a preservação deixa de ser algo imposto, interioriza-seetorna-sevital.Aeducação patrimonial tem um papel de ressignificar a relação de afeto pelo patrimônio e, desse modo, ao se trabalhar os conceitos sobre patrimônio, memória e cultura com a população, cria-se um canal para a conscientização sobre o espaço público, seus direitos e deveres, estimulando, assim, a cidadania dos mais diversos grupos: crianças e adolescentes, pessoas de terceira idade, portadores de necessidades especiais etc.

à luz desta interpretação da história, devese reivindicar a apropriação dos movimentos sociais, da sociedade civil organizada e do povo, de maneira geral, sobre o patrimônio cultural, pois este pertence à população que, juntamente com os órgãos públicos, devem ser os guardiões patrimoniais, o que torna necessária uma mudança de postura e de atitude. Portanto, acredito ser louvável a predisposição da população, a fim de se tornar guardiã do patrimônio da história cultural brasileira.

\section{Referências}

ARENDT, H. A condição humana. Rio de Janeiro: Forense Universitária, 1987.

BARROSO, Ari. Upa, upa! (Meu trolinho). São Paulo, RCA, 1941, disco sonoro.

BRASIL. Constituição (1988). Constituição da República Federativa do Brasil. Brasília, DF: Senado Federal, 1988.

. Decreto-Lei № 25. Organiza a proteção do patrimônio histórico e artístico nacional. 1937. Disponível em: <http:// http://www.planalto.gov.br/ccivil_03/decreto-lei/del0025.htm>. Acesso em: 23 fev. 2012

CAMARGO, H. L. Conceitos de patrimônio: técnica ou ideologia? 2013. Disponível em: < http:// http://www.historiaehistoria.com.br/materia.cfm?tb=artigos\&id=26>. Acesso em: 15 fev. 2012.

CASTELLS, M. O poder da identidade. 5. ed. São Paulo: Paz e Terra, 2000. 
FREIRE, P. Pedagogia do Oprimido. Rio de Janeiro: Paz e Terra, 1987.

FUNARI, P. P. A. Os desafios da destruição e conservação do patrimônio cultural no Brasil. Trabalhos de Antropologia e Etnologia, Porto, v. 41, p. 23-32, 2001.

FUNARI, P. P. A.; CARVALHO, A. V. O patrimônio em uma perspectiva crítica: o caso do Quilombo dos Palmares. Diálogos, Maringá, v. 9, n. 1, p. 34, 2005.

HALL, S. Identidade cultural e diáspora. Revista do Patrimônio Histórico e Artístico Nacional, Rio de Janeiro, n. 24, p. 68-75, 1996.

HORTA, M. de L. P.; GRUnBerG, E.; MONTEIRO, A. Q. Guia Básico de Educação Patrimonial. Brasília: Instituto do Patrimônio Histórico e Artístico Nacional, Museu Imperial, 1999.

LEMOS, C. A.C. O que é patrimônio histórico. 5. ed. São Paulo: Brasiliense, 1987.

MACIEL, C. A. A. A retórica da paisagem: um instrumento de interpretação geográfica. Rio de Janeiro: Espaço e Cultura, 2009.

MINAS GERAIS. Lei no 12.040, de 28 de dezembro de 1995. Dispõe sobre a distribuição da parcela de receita do produto da arrecadação do ICMS pertencente aos Municípios, de que trata o inciso II do parágrafo único do artigo 158 da Constituição Federal, e dá outras providências. Disponível em: < http://www.almg.gov.br>. Acesso em: 18 ago. 2011.

PELEGRINI, S. Cultura e natureza: os desafios das práticas preservacionistas na esfera do patrimônio cultural e ambiental. Revista Brasileira de História, São Paulo, v. 26, n. 51, jan.-jun. 2006.

QUEIROZ, M. A. N. F. de. Ouro Preto e Mariana. In: ARANTES, A. A. (Org.). Produzindo o passado: estratégias de construção do patrimônio cultural. São Paulo: Brasiliense, 1984.

TAPETE VERMELHO. Direção: Luís Alberto Pereira. Brasil: Pandora Filmes, 2006. 1 DVD (102 min), NTSC, son., color.

Submetido em 23 de abril de 2012.

Aprovado em 4 de agosto de 2012. 